\title{
Network Ties, Social Capital, and Knowledge Management
}

\author{
Dong-Mei Lee, Yu-Xia Fu, Lee-Yuan Wang, and Tao Nie
}

\section{ABSTRACT}

As an invisible informal structure embedded within an organization, social network is closely related to the knowledge management activities and knowledge management strategies of the organization. The social network has the potential to obtain the right information or knowledge at the right time through the weak ties of the organization, to realize effective knowledge sharing in the organization with strong ties, and to commercialize knowledge using social capital to achieve economic success. By dividing the knowledge management process into three stages, including knowledge acquisition, knowledge sharing, and knowledge commercialization, the paper examines the role of weak ties, strong ties and social capital in knowledge management, and puts forward three hypotheses. Finally, the paper puts forward management suggestions for the construction of social networks in enterprises.

Keywords: Knowledge management, Strong ties, Social capital, Weak ties.
Submitted : September 06, 2021

Published : October 17, 2021

ISSN: 2507-1076

DOI: $10.24018 / \mathrm{ejbmr} .2021 .6 .5 .1090$

Dong-Mei Lee *

School of Economics and Management, Shanxi University, Taiyuan, P.R. China. (e-mail: lidm@sxu.edu.cn)

Yu-Xia Fu

School of Economics and Management,

Shanxi University, Taiyuan, P.R. China.

(e-mail: fyx19990503@163.com)

Lee-Yuan Wang

School of Economics and Management, Shanxi University, Taiyuan, P.R. China.

(e-mail: 18035668877@163.com)

Tao Nie

School of Economics and Management, Shanxi University, Taiyuan, P.R. China. (e-mail: nt66688882021@163.com)

*Corresponding Author

\section{INTRODUCTION}

In the era of knowledge economy, knowledge is the key resource for enterprises to gain competitive advantage. With China's accession to the WTO, Chinese enterprises are faced with the reality of "going out" to be exposed to global competition. Under such background, effective knowledge management and organizational learning, including crossorganizational learning and intra-organizational learning, are the only ways for organizations to become more competitive. The focus of knowledge management is the ability of enterprises to create, transfer and use knowledge, which is to build enduring competitive advantage.

Although firms' behavior is always carried out in the context of certain social relations, most of the existing research regards enterprises as atomic agents, ignoring the impact of social networks as background on such behavior. The social network theory stemmed from sociology provides the concept for analyzing social phenomena and is gradually applied to many fields, but this method of analysis is seldom applied in enterprise knowledge management.

The main research objectives of this paper are to divide the knowledge management process into three stages: knowledge acquisition, knowledge sharing and knowledge commercialization Then we apply social network theory to the knowledge management process of enterprises, by examining the role of social network structure and social network content in different stages of knowledge management process. We aim to enrich the existing research on knowledge management and social network analysis and provide managerial implications for enterprises to build social networks to gain competitive advantage.

\section{LITERATURE REVIEW}

Research on social networks stems from anthropologists' discussions of interpersonal interactions in complex societies. Social network refers to the relatively stable system composed of social relations between certain agents. The most basic unit of analysis is various "relationship ". The social network theory holds that neoclassical economics and neo-institutional economics only study physical capital and human capital, ignoring the role of social capital in economic development. Social capital is the social structure that creates value and promotes individual behavior. Social capital emerges when changes of people's relationships can promote instrumental action.

Since the 1990s, social network theory has been accepted by the American sociology and management circles and widely used [1]-[4]. Recently, some studies have begun to examine the relationship between social networks and knowledge management and corporate performance. For example, Hansen [5] has shown that weak ties help in the search for knowledge, but hinder the transfer of complex knowledge, which must rely on strong ties. Research by Levin \& Cross [6] shows that weak ties help to acquire nonredundant knowledge, and competency-based trust relationships are important for acquiring implicit 
knowledge. Hoffman et al. [7] shows that firms with higher social capital tend to have a higher level of knowledge management and thus lead to better performance. Tsai [8] believes that organizations that occupy the center of the network can produce more innovation and better performance from a network perspective of organizational learning. Raudeliuniene et al. [9] examined the impact of information technologies and technology-enabled social networks on the efficiency of knowledge management processes in the Middle Eastern audit and consulting companies.

To sum up, some researchers have begun to apply the concepts of social network to knowledge management research, but most of the research only involves a certain stage of the knowledge management process, not from a systematic point of view to study the impact of social networks on different stages of knowledge management. In this paper, we divide the knowledge management process into three stages: knowledge acquisition, knowledge transfer and knowledge commercialization, and examines the impact of social networks on the three stages of knowledge management.

\section{THEORETICAL BACKGROUND AND HYPOTHESIS DEVELOPMENT}

As an invisible informal structure embedded in the organization, the social network is closely related to the organization's knowledge management activities and knowledge management strategy and is a valuable social resource of the organization. Social networks have the potential to gain information by crossing the boundaries of a group or organization. Therefore, the establishment of a sound social network to improve the organization's information stock can promote and guarantee the success of organizational knowledge management.

\section{A. Weak Ties and Knowledge Acquisition}

The theory of weak ties is proposed by Granovetter [1], a sociology professor at Stanford University. The so-called "weak ties" refers to "non-recurring, low-intimate relationships". Because " Birds of a feather flock together.", similar people may form a group because of the same interests, personality, members of the group.

The weak ties between two nodes have a strong heterogeneity and can provide non-redundant knowledge for the organization. This non-redundant knowledge is either new information about knowledge use opportunities or knowledge related to specific projects [5]. Weak ties have information benefits in the form of access, timing, and referring [2]. "Access to information" enables an individual to gain valuable information and who can use it. "Timing" enables an individual to become an early acquirer of valuable information. "Referring" is a key factor in turning the individual's ability to acquire knowledge at the right time into reality. Weak ties can enable enterprises to access more information related to internationalization, including international market information, international business cooperation information and host government policy information. In addition, since explicit knowledge can be expressed in the language of the system, it can be shared in the form of data, scientific formulas, instruction manuals, manuals, etc., it can be stored in a single location, can be transferred in time and space without relying on individuals, and explicit knowledge is easy to diffuse and communicate [10]. Because weak ties have the advantage of knowledge search in the network, we make the assumption:

H1: Weak ties have a positive effect on organizations' acquisition of explicit knowledge.

\section{B. Strong Ties and Knowledge Sharing}

Strong ties refer to the "frequent interaction, emotional closeness" of the relationship. The cultivation of strong linkages often requires more time and effort between individuals than weak ties. Granovetter [1] argues that strong ties are homogeneous. Strong ties are made between people with more similar social characteristics, who understand things and experience events that are often the same, and who, because of their close contacts, mutual understanding and easy access to each other's trust, have a subjective perception that facilitates knowledge sharing.

Liberman et al. [11] found that Japan's carmakers' competitive advantage comes not only from zero inventory management, but also from bilateral and multilateral knowledge-sharing networks they establish and maintain with suppliers. Toyota is recognized by the corporate community as a "model of continuous learning and improvement". Through the establishment of supplier associations between Toyota and automotive suppliers, and well-trained consultants sent to supplier companies to teach TPS (Toyota's Production System) knowledge free of charge. It is precisely because the network members maintain close interrelationship, optimize the sub-network structure under the unified network, and thus enhance the effectiveness of knowledge sharing network.

Because of frequent communication between members with strong tie, strong emotional connections are often formed between them and are easy to gain trust with each other, and highly trusted relationships make people more willing to share resources and valuable information. This strongly connected social network not only reduces the cost of access to information, technology, and resources, but also improves the efficiency of implicit knowledge sharing [12]. In terms of knowledge characteristics, since implicit knowledge is considered to be a skill acquired through personal experience (Know-how), it is limited to a particular context, rooted in people's actions and inter-relationships, and difficult to code [13], [14]. Strongly connected organization members communicate in a "small circle" that facilitates deep communication and information exchange, making it easier for them to communicate and apply the hidden knowledge they gain. Therefore, we make the assumption that:

H2: Strong ties have a positive effect on organizations' knowledge sharing.

\section{Social Capital and Knowledge Commercialization}

The social capital theory pays attention to the nature of resources embedded in the network. Social capital refers to the ability of individuals to access scarce resources and benefit from them through social connections. Scarce resources in this case include power, status, wealth, capital, knowledge, opportunities, information, etc. [15]. Individuals 
can acquire resources through stable connections established with social groups and organizations as members of social groups or organizations, or through social networks to acquire social resources such as power, wealth, prestige, etc., thus achieving their personal goals. Lin et al. [16] investigated an individual's job-seeking behavior and found that it is not the strength of the connection that has an advantage, but that the connection may come into contact with the person who have the resources needed to achieve the instrumental goal. The important resources for individual development through social networks are the key to their success in their work.

Similar to Putnam's [15] definition of social capital, Bian and Qiu [17] regard enterprises as nodes in the network that have various connections in all aspects of the economic field, and the ability to access scarce resources through vertical, horizontal and social linkages is the social capital of enterprises. Bian \& Zhang [18] also operationalize the concept of social capital as a company seeking and acquiring scarce resources within the industry through its vertical hierarchical linkages with government authorities.

Knowledge commercialization refers to the process by which an organization translates knowledge into innovative products or services and successfully brings it to market for financial or strategic objectives, such as setting industry standards or achieving learning benefits [19]. The role of social capital is to reduce the probability and cost of supervision of opportunistic behavior on the one hand, and to increase the company's opportunities, access to resources and flexibility on the other [12]. This exists not only in the capitalist market economy, but also in the transition economy. For example, in a Chinese company in the context of transformation, informal institutional constraints will play a more important role in regulating economic exchanges[20] Chinese companies may rely more on relationship-based business models when it is difficult to obtain the resources and technology they need through the marketplace. For instance, companies with state-owned background can guarantee some customers because of the personal contact of the top executive. Therefore, we make the assumption that:

H3: Social capital has a positive impact on the commercialization of knowledge in an organization.

\section{CONCLUSIONS}

The neoclassical framework is often used as a theoretical basis for studying inter-firm relationships because it represents the core principles of most economic methods. Under this framework, based on rational assumptions, the competitive relationship between individuals will maximize the overall social welfare, so that the "invisible hand" is considered to be a reasonable mechanism to ensure optimal allocation of resources. Enterprise knowledge management is always carried out under the background of certain social relations. However, most of the existing research regards enterprises as atomic agents, ignoring the impact of social networks as background on corporate behavior. Although some economists have realized that there is a big gap between theoretical models and the real world, they still pay little attention to examples of departures from ideal states. In the 1930s, the British anthropologist Radcliffe Brown first proposed the concept of "social network" and applied it to the discussion of interpersonal interaction in complex societies.

Under the background of technological innovation acceleration, more and more enterprises are beginning to use the organization mode of inter-enterprise coordination to organize knowledge transactions and production activities in order to obtain complementary resources and capabilities. Firms embedded in the network can enhance their innovation ability through knowledge sharing and interorganizational learning, thus maintaining high flexibility in the face of uncertain markets. As an invisible informal structure embedded within the organization, the social network is closely related to the organization's knowledge management activities and knowledge management strategy. The social network has the potential to obtain the right information or knowledge at the right time through the weak ties of the organization, to realize effective knowledge sharing in the organization with strong ties, and to commercialize knowledge using social capital to achieve economic success.

\section{REFERENCES}

[1] M. S. Granovetter, "The strength of weak ties", American Journal of Sociology, vol. 78, no. 6, pp. 1360-1380, 1973.

[2] R. Burt, Structural holes. Cambridge, MA: Harvard University Press, 1992.

[3] R.D. Putnam, Making democracy work. Princeton, NJ: Princeton University Press, 1993.

[4] B. Nooteboom, Inter-firm alliances: Analysis and design. London Routledge, 1999.

[5] M. T. Hansen, " The search-transfer problem: The role of weak ties in sharing knowledge across organization subunits", Administrative Science Quarterly, vol. 44, no. 1, pp. 82-111, 1999.

[6] D. Z. Levin, R. Cross, "The strength of weak ties you can trust: The mediating role of trust in effective knowledge transfer", Management Science, vol. 50, no. 11, pp. 1477-1490, 2004.

[7] J. J. Hoffman, M. L. Hoelscher, and K. Sherif, "Social capital, knowledge management, and sustained superior performance", Journal of Knowledge Management, vol. 9, no. 3. pp. 93-100, 2005.

[8] W. Tsai, "Knowledge transfer in intraorganizational networks: Effects of network position and absorptive capacity on business unit innovation and performance", Academy of Management Journal, vol. 44, no. 5, pp. 996-1004,2001.

[9] J. Raudeliuniene, E. Albats, M. Kordab, "Impact of information technologies and social networks on knowledge management processes in Middle Eastern audit and consulting companies", Journal of Knowledge Management, 2020, ahead-of-print.

[10] M. Schultz, The Uncertain Relevance of Newness: Orgnizational Learning and Knowledge Flows", Academy of Management Journal, vol. 44, no.4, pp. 661-681, 2001.

[11] M. Liberman, M. Sako, K. Wada, L. Demeester, The Productivityenhancing Impact of Suppliers' Associations in the Japanese Auto Industry. IMVP Sponsors Forum. Kyung, Ju. Korea, 1997.

[12] B. Uzzi, "The Sources and Consequences of Embeddedness for the Economic Performance of Organizations: The Network Effect", American Sociological Review, vol. 61, pp. 674-698, 1996.

[13] M. Polanyi, Personal Knowledge: Toward a Post-Critical Philosophy. New York: Harper Torchbooks, 1962.

[14] I. Nonaka. "A dynamic theory of organizational knowledge creation", Organization Science, vol. 5, no. 1,pp. 40-54, 1994.

[15] R. Putnam, "Bowling Alone: America's Declining Social Capital", Journal of Democracy,vol.6, no. 1, pp.65-78, 1995.

[16] N. Lin, W. M. Ensel, J. C. Vaughn, "Social resources and strength of ties: structural factors in occupational status attainment", American Sociological Review, vol.46, no. 4,pp.393-405, 1981.

[17] Y. J. Bian, H. X. Qiu, "Social capital and its functions", Chinese Social Science, no. 2, pp. 87-99, 2002.

[18] Y. J. Bian, W.H. Zhang. "Economic system, social network and job mobility", Chinese Social Science, no. 2, pp. 77-89, 2001. 
[19] S. H. Park, Y. Luo, "Guanxi and Organizational Dynamics: Organizational Networking in Chinese Firms", Strategic Management Journal, vol. 22, no. 5, pp. 455-477, 2001.

[20] U. Lichtenthaler, "External commercialization of knowledge: Review and research agenda," International Journal of Management Reviews, vol. 7, no. 4, pp. 231-255, 2005.

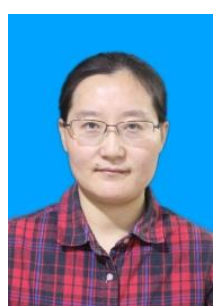

Dong-Mei Lee is an associate professor in the department of Accounting, School of Economics and Management, Shanxi University, P.R. China. She received his Master's degree from School of Mathematics, Shanxi University, P.R. China, and Ph. $\mathrm{D}$ in management from School of Economics and Management, Shanxi University, P.R. China. Her area of specialization is times series analysis, technology management and standard battles.

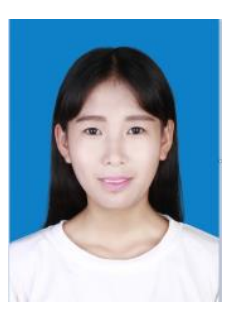

Yu-Xia Fu is a postgraduate student in School of Economics and Management, Shanxi University, P.R. China. She received his B.A degree from Anyang Normal University, P.R. China. Her current research interests focus on innovation management and standardization, Machine learning.

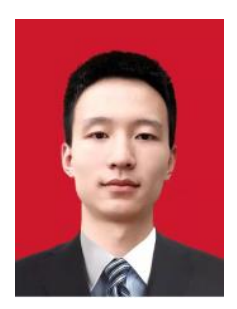

Lee-Yuan Wang is a postgraduate student in School of Economics and Management, Shanxi University, P.R. China. He received his B.A degree from Shanxi University, P.R. China. His current research interests focus on innovation management and standardization, Machine learning.

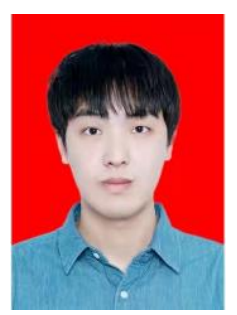

Tao Nie is a postgraduate student in School of Economics and Management, Shanxi University, P.R. China. He received his B.A degree from North University of China. His current research interests focus on innovation management and standardization. 